\title{
Optimal scheduling of multi-carrier energy networks considering liquid air energy storage
}

\author{
Peng Wang \\ School of Information Science and Engineering \\ Central South University \\ Changsha, China \\ wp10751@csu.edu.cn \\ Wei Wang \\ College of Electrical Engineering \\ Guangxi University \\ Nanning, China \\ specialwangwei@163.com \\ Jahedul Islam Chowdhury \\ School of Water, Energy and Environment \\ School of Management \\ Cranfield University \\ Bedford, UK \\ J.Chowdhury@cranfield.ac.uk
}

\author{
Chunsheng Wang* \\ School of Information Science and Engineering \\ Central South University \\ Changsha, China \\ wangcsu@csu.edu.cn
}

Jiamin Li

School of Information Science and Engineering Central South University

Changsha, China

charminglee@csu.edu.cn

Nazmiye Balta-Ozkan

School of Water, Energy and Environment

Cranfield University

Bedford, UK

n.ozkan@cranfield.ac.uk
Yukun $\mathrm{Hu}$

School of Management

Cranfield University

Bedford, UK

Yukun.Hu@cranfield.ac.uk

\author{
Liz Varga \\ School of Management \\ Cranfield University \\ Bedford, UK \\ liz.varga@cranfield.ac.uk
}

\begin{abstract}
Energy storage technologies are crucial to the future integrated energy system (IES) in the context of energy internet (EI). Liquid air energy storage (LAES) technology has been widely researched and implemented in the United Kingdom, since there are no special restrictions on geography compared to other technologies. However, there is little attention on LAES in China. In this paper, a linear programming model for the optimal scheduling of multicarrier energy networks considering LAES is established based on the concept of cryogenic energy hub, that is LAES-HUB. The results show that the daily operation cost of LAES-HUB model is 43735.28 RMB, which is even higher than the energy networks works without LEAS. LAES can achieve load shifting through peak and off-peak operations, providing an auxiliary function for energy balance in multi-carrier energy networks.
\end{abstract}

Keywords-Energy Internet, Integrated Energy System, Energy Storage, Optimal Scheduling, Linear Programming

\section{INTRODUCTION}

The integrated energy system (IES) is the product of deep integration of multi-carrier energy networks with the internet. China is at a critical stage of industrialization and urbanization, and energy consumption will continue to grow $[1,2]$. IES is the key to realizing China's future energy revolution by establishing a deep coupling system of supply, distribution and utilization of various forms of energy, such as electricity, heat, cold and gas. As the physical carrier of the energy internet (EI), the construction of IES is conducive to the large-scale development of renewable energy, improving the comprehensive utilization of various energy sources, and achieving the sustainable development of social energy. IES has become a promising strategic direction in energy field.

The concept of energy hub was first proposed in [3], which is actually a microcosm of IES. Many comprehensive

\footnotetext{
*Corresponding author. E-mail.: wangcsu@csu.edu.cn.

This research is supported by the National Natural Science Foundation of China (61573381) and the Engineering and Physical Sciences Research Council (EPSRC, EP/P004636/1, UK)
}

and in-depth studies have been conducted on modeling, optimization of system structure and analysing operational strategies of IES [4-9]. As a key component of the energy hub, in the future energy storage technology will be vigorously implemented in the context of EI to achieve the optimal economic operation of IES. In recent years, many studies have focused on implementing battery energy storage (BES) [5,6] or compressed air energy storage (CAES) [10] in multi-carrier energy networks. However, there was little attention in the implementation of liquid air energy storage (LAES) technology in China. LAES is a promising and one of the few storage technologies that can achieve large-scale applications without geographical restrictions, which is relatively mature and has been commercialized in the United Kingdom [11,12].

In view of the above research gap and the concept of energy hub, a linear programming model of LAES-HUB for multi-carrier energy networks optimization scheduling is established. The proposed model is then successfully applied to the case study of a regional multi-carrier energy networks. The paper is organized as follows: Section II describes the methodology and data; Section III presents the empirical analysis of the LAES-HUB model; and Section IV draws important conclusions.

\section{METHODOLOGY AND DATA}

In this section, the concept of LAES is briefly introduced, and then the modeling process and data sources of the proposed LAES-HUB model are thoroughly described.

\section{A. The general concept of LAES}

In general, the thermodynamic cycle of LAES consists of three processes: air liquefaction, liquid air energy storage and air evaporation, as shown in Fig. 1. Heating and cooling energy storage processes are not considered in this figure since we only consider the charging and discharging processes of LAES in this study. In the process of charging, the surplus power from regional grid drives an air 
liquefaction device to compress and refrigerate air to its liquid state, and then liquid air is stored in a low pressure insulated tank. In the process of discharging, liquid air is pumped to a heat exchanger at a high pressure that evaporates air and then expanded in a turbine to drive a coupled generator to produce electricity $[11,12]$.

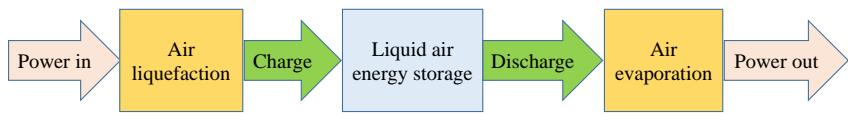

Fig.1. The general concept of LAES

\section{B. LAES-HUB model}

The LAES-HUB model, based on the concept of energy hub, is shown in Fig. 2. The inputs of the model are electricity from the selected regional grid, natural gas and renewable energy sources (RESs). The outputs are electricity, heating, cooling for electricity load, heating load and cooling load respectively. The crucial components of this model are various energy storage and conversion units (ESCU), which are next thoroughly discussed.

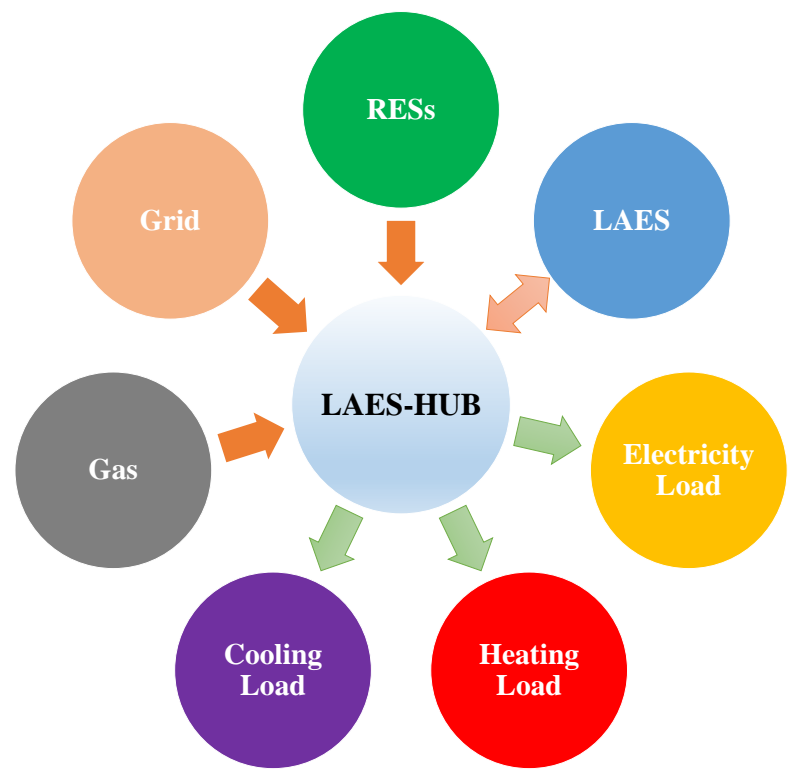

Fig. 2. The concept for the proposed LAES-HUB

Fig. 3 displays the detailed framework for the proposed LAES-HUB model. Wind power and solar PV (photovoltaic) power are considered as RESs in this model. Energy storage and conversion units contain the LAES, transformer, combined heat and power (CHP), furnace, chiller boiler (CB) and electricity heat pump (EHP).The inputs and outputs of the ESCU are given in Table I.

TABLE I. INPUT AND OUTPUT OF ESCU

\begin{tabular}{|c|c|c|c|}
\hline $\begin{array}{c}\text { Energy storage and } \\
\text { conversion units }\end{array}$ & $\begin{array}{c}\text { Input } \\
\text { energy }\end{array}$ & $\begin{array}{c}\text { Output } \\
\text { energy }\end{array}$ & $\begin{array}{c}\text { Efficiency } \\
\text { coefficient }\end{array}$ \\
\hline LAES & Electricity & Electricity & $\eta$ \\
\hline Transformer & Electricity & Electricity & $\eta_{e e}$ \\
\hline CHP & Gas & Electricity & $\eta_{g e}$ \\
\hline CHP & Gas & Heating & $\eta_{g h}$ \\
\hline Furnace & Gas & Heating & $\eta_{f g h}$ \\
\hline CB & Heating & Cooling & $\eta_{h c}$ \\
\hline EHP & Electricity & Heating & $C O P$ \\
\hline EHP & Electricity & Cooling & $C O P$ \\
\hline
\end{tabular}

\section{1) Objective Function}

The objective function (1) of this model is to minimize the daily operating cost $(T)$ of multi-carrier energy networks, including electricity procurement cost from the regional grid $\left(T_{\text {ele }}\right)$, natural gas procurement cost $\left(T_{\text {gas }}\right)$ and environmental $\operatorname{cost}\left(T_{\text {env }}\right)$. The symbols $\lambda_{\text {ele }}(\mathrm{t}), \lambda_{\text {gas }}(\mathrm{t})$ represent electricity and natural gas price in time $t$ respectively $(\mathrm{RMB} / \mathrm{kWh})$, while $\rho$ represents the environment cost coefficient for carbon dioxide $\left(\mathrm{CO}_{2}\right)$ emissions $(\mathrm{RMB} / \mathrm{kg})$ [4]. Similarly, $\omega_{\text {ele }}(\mathrm{t})$, $\omega_{\text {gas }}(\mathrm{t})$ are equivalent $\mathrm{CO}_{2}$ emission coefficient for electricity and gas respectively (kg/kWh) [6].

$$
\begin{aligned}
& \min T=\left(T_{\text {ele }}+T_{\text {gas }}+T_{\text {env }}\right) \\
& T_{\text {ele }}=\sum_{t=1}^{24}\left(\lambda_{\text {ele }}(t) \times P(t)\right) \\
& T_{\text {gas }}=\sum_{t=1}^{24}\left(\lambda_{\text {gas }}(t) \times G(t)\right) \\
& T_{\text {env }}=\rho \times \sum_{t=1}^{24}\left(\omega_{\text {ele }} \times P(t)+\omega_{\text {gas }} \times G(t)\right)
\end{aligned}
$$

\section{2) Physical Constraints}

Electricity demand and supply balance constraints are applied as follows:

$$
\begin{aligned}
& \eta_{e e} \times P_{1}(t)+\eta_{g e} \times G_{1}(t)+P_{d}(t)=L_{e}(t)+P_{3}(t) \\
& P(t)=P_{1}(t)+P_{2}(t) \\
& P_{1}(t)=P_{c}(t)
\end{aligned}
$$

Heating and cooling demand and supply balance constraints are shown in (3), where $B_{h}(t)$ and $B_{c}(t)$ are used as binary variables to make sure the EHP either works in cooling state or heating state.

$$
\begin{aligned}
& \eta_{g h} \times G_{1}(t)+H_{2}(t)+H_{e h p}(t)=L_{h}(t) \\
& \eta_{h c} \times H_{1}(t)+C_{e h p}(t)=L_{c}(t) \\
& G(t)=G_{1}(t)+G_{2}(t) \\
& \eta_{f g h} \times G_{2}(t)=H_{1}(t)+H_{2}(t) \\
& H_{e h p}(t)+C_{\text {ehp }}(t)=P_{3}(t) \times C O P \\
& H_{e h p}(t) \leq H_{\text {ehpmax }} \times B_{h}(t) \\
& C_{\text {ehp }}(t) \leq C_{\text {ehpmax }} \times B_{c}(t) \\
& B_{h}(t)+B_{c}(t) \leq 1
\end{aligned}
$$

LAES constraints are shown in (4), where $\eta$ is the round trip efficiency. $S E_{\max }, S P_{\max }$ are the capacity and power limitation of LAES respectively [13], $R_{c}(t)$ and $R_{d}(t)$ are used as binary variables to make sure the LAES either works in charging state or discharging state.

$$
\begin{aligned}
& \operatorname{LAES}(t)=\operatorname{LAES}(t-1)+\left(P_{c}(t) \times \eta-P_{d}(t)\right) \times \Delta t \\
& \operatorname{LAES}(t) \leq S E_{\max } \\
& P_{c}(t) \leq S P_{\max } \times R_{c}(t) \\
& P_{d}(t) \leq S P_{\max } \times R_{d}(t) \\
& R_{c}(t)+R_{d}(t) \leq 1
\end{aligned}
$$

\section{Data Sources}

Fig. 4 illustrates the power supply and demand data.The output power data for solar PV and wind were derived from [4].The power demand data for electricity, heating and cooling were obtained from $[4,5]$. The hourly energy prices for electricity and natural gas were also obtained from [5], as shown in Fig. 5. To match the power data of this multicarrier energy networks, the LAES with capacity of 
$350 \mathrm{~kW} / 2.5 \mathrm{MWh}$ was adopted for this research. The selected LAES will therefore provide a $S E_{\max }$ of $2.5 \mathrm{MWh}$ and a $S P_{\max }$ of $350 \mathrm{~kW}$. Detailed data for the chosen LAES can be found in $[11,12]$. In current analysis, we assumed that the charging and discharging processes of the LAES are in an ideal state. Therefore, the round trip efficiency we adopted for this LAES is 0.6. Other data for the ECSU were obtained from [4-9].

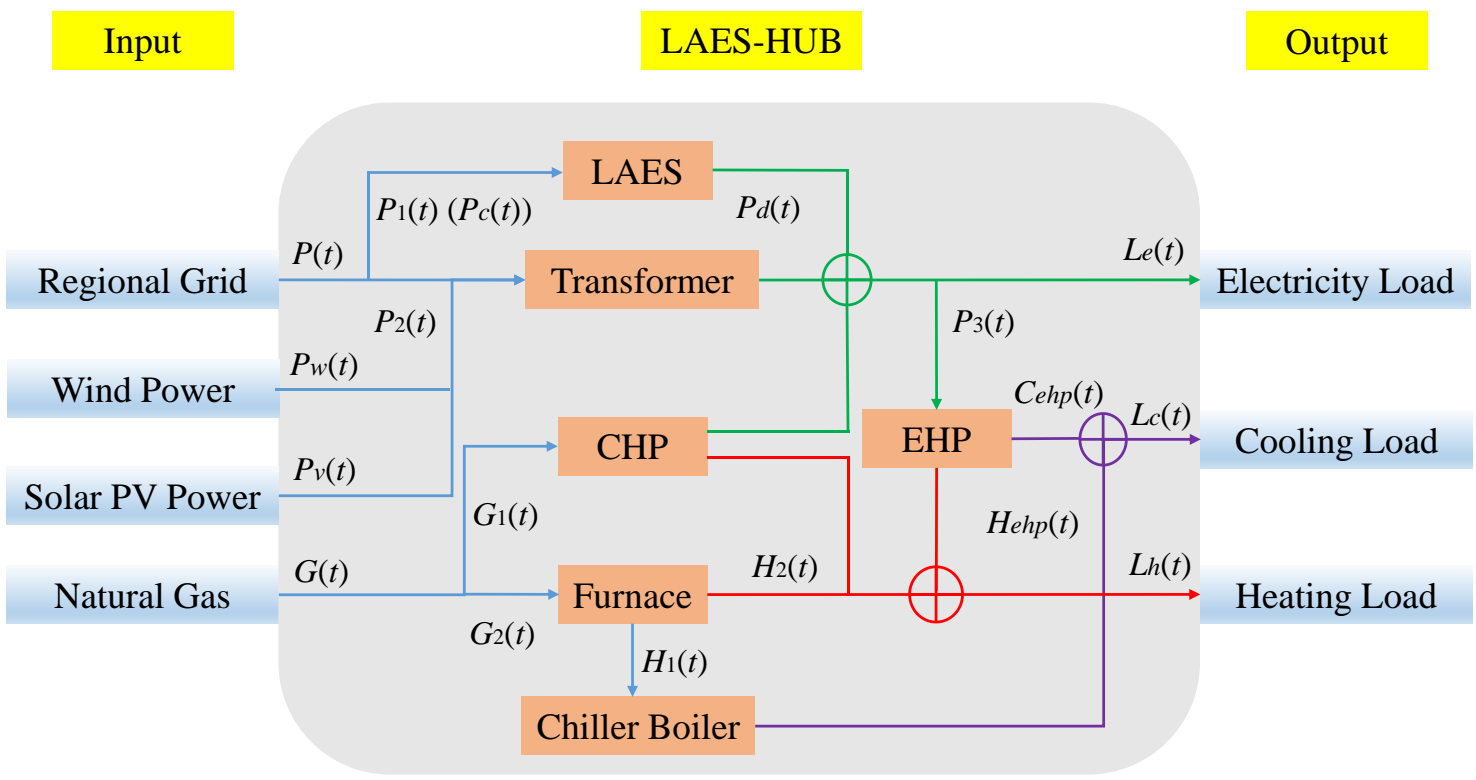

Fig. 3. Framework of the proposed LAES-HUB model

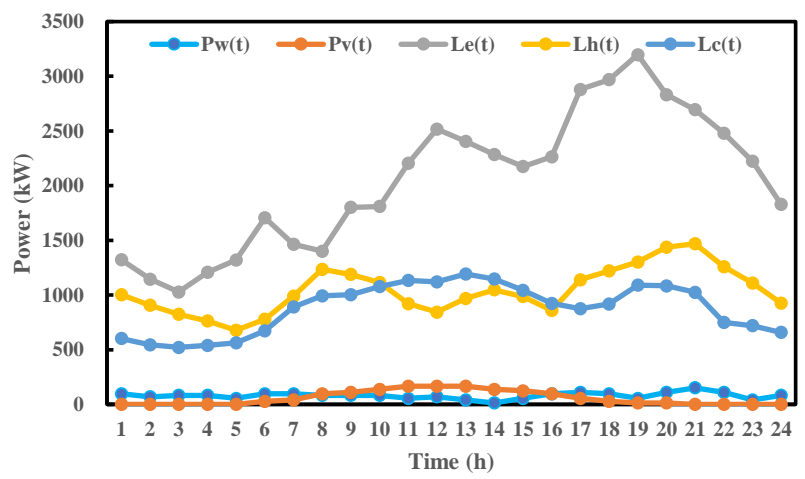

Fig. 4. Power supply (from PV and wind) and demand (for Electricity, Heating, Cooling)

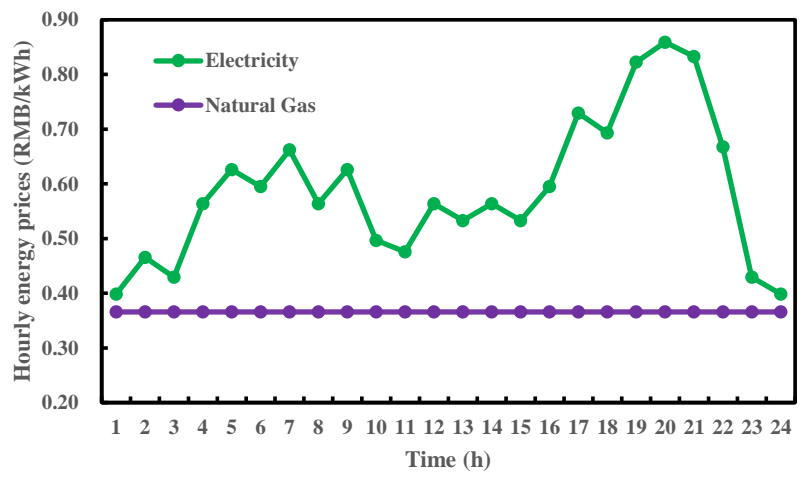

Fig. 5. Hourly prices for electricity and natural gas

\section{RESUlTS AND DISCUSSION}

This section presents results of the simulation and analyses of daily operation cost, energy input for electricity and natural gas, and optimal operation state of LAES. It is expected that these results will have far-reaching influences on future planning of IES.

\section{A. Daily operation cost}

As can be seen from Table II, the daily operation cost of our proposed LAES-HUB model is 43735.28 RMB. However, it is only $42197.72 \mathrm{RMB}$ for this multi-carrier energy networks without LAES, even about $3.52 \%$ less than the LAES-HUB model.

The result obtained from the analysis is as expected since we did not take the internal heating and cooling processes of LAES into account, and we did not make full use of the heating and cooling energy released from the charging and discharging processes of LAES. Moreover, the capacity of the LAES is quite small to match our power data, and the round trip efficiency we adopted is only 0.6 , much lower than those mature energy storage technologies with efficiency over 0.9 , which may have played a decisive effect. These factors have a large influence on the above results.

The abovementioned factors show that the LAES-HUB technology can be useful in a larger scale, and all those complicated processes involved in LAES should be taken into account, to take full advantage of LAES when integrating this technology into future IES.

TABLE II. COMPARISON OF OPERATING COSTS

\begin{tabular}{|c|c|}
\hline System operation state & Daily operation cost (RMB) \\
\hline Without LAES & 42197.72 \\
\hline With LAES (LAES-HUB) & 43735.28 \\
\hline
\end{tabular}

\section{B. Energy input}

Fig. 6 illustrates the energy input of electricity and natural gas to the LAES-HUB. It is clear that the change trends of energy input curves are similar to the electricity and heating demand curves in Fig. 4. This means that this multi-carrier energy networks mainly depends on energy input to maintain its energy supply and demand balance, and LAES has only auxiliary effect on this system. 


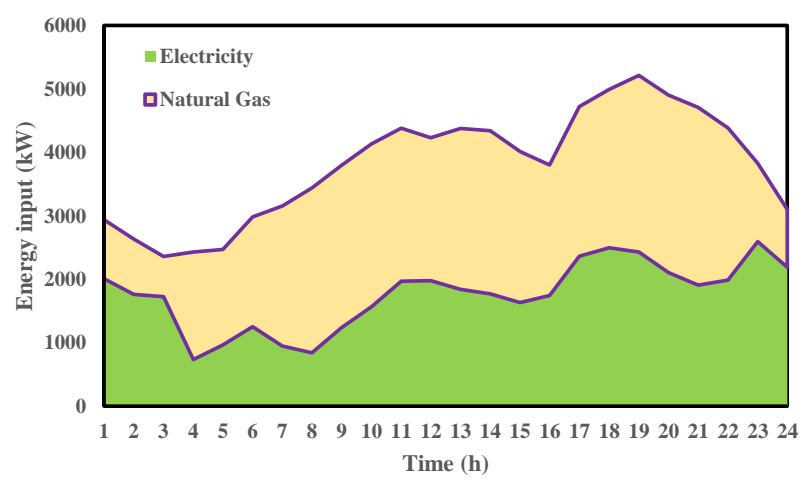

Fig. 6. Optimal input of electricity and natural gas

\section{Optimal operation state of LAES}

Fig. 7 displays the optimal operation state of the LAES in the multi-carrier energy networks. This figure shows that the LAES has perfectly realized the concept of peak and offpeak operations [14]. In other words, the LAES stores energy in off-peak time, and releases energy in peak time.

During the time of off-peak periods (e.g. from $1 \mathrm{am}$ to 4am and 9am to $12 \mathrm{am}$, the demand for the energy networks is low), the LAES worked in charging state, and surplus electricity was stored. In contrast, during the peak periods (e.g. from $18 \mathrm{pm}-22 \mathrm{pm}$, demand is high), the LAES worked in discharging state, and stored electricity was released to meet the balance between supply and demand.

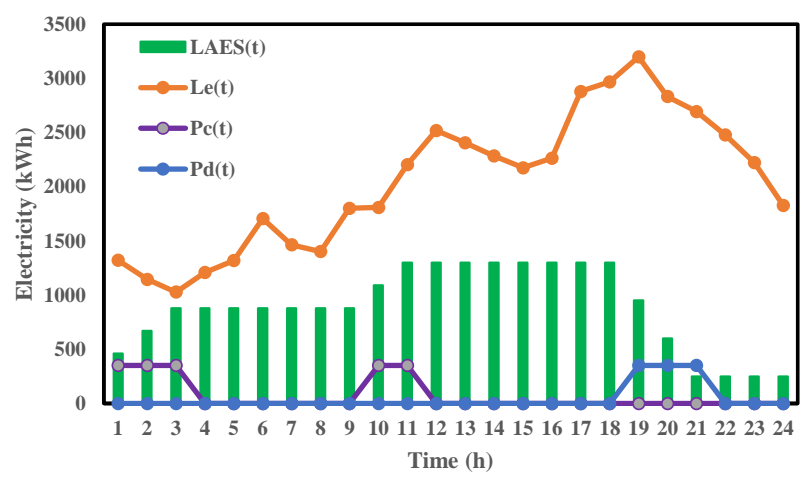

Fig. 7. Optimal operation state of LAES

\section{CONCLUSIONS}

In this paper, a promising energy storage technology LAES was integrated in a multi-carrier energy networks, and a LAES-HUB model was established based on the concept of energy hub. The objective function of this model is to minimize the daily operation cost, through which some meaningful conclusions have been obtained and summarized as follows:

1) The daily operation cost of LAES-HUB model is 43735.28 RMB, which is even higher than the energy networks works without LEAS. This result was as expected due to the fact that an internal heating and cooling processes of LAES was ignored.

2) Electricity demand and supply of the LAES-HUB system mainly depended on the energy input, and the LAES only played an auxiliary role.

3) The LAES used in the proposed LAES-HUB can achieve load shifting through peak and off-peak operations, providing an auxiliary function for energy balance in the multi-carrier energy networks.

\section{REFERENCES}

[1] P. Wang, C. Wang, Y. Hu and Z. Liu, "Analysis of energy consumption in hunan province (China) using a LMDI method based LEAP model," Energy Procedia, vol. 142, pp. 3160-3169, 2017.

[2] P. Wang, C. Wang, Y. Hu, L. Varga and W. Wang, "Power Generation Expansion Optimization Model Considering MultiScenario Electricity Demand Constraints: A Case Study of Zhejiang Province, China," Energies, vol. 11, no. 6, 2018.

[3] M. Geidl, G. Koeppel, P. Favre-Perrod, B. Klockl, G. Andersson and K. Frohlich, "Energy hubs for the future," IEEE Power and Energy Magazine, vol. 5, no. 1, pp. 24-30, 2007.

[4] T. Ma, J. Wu. L. Hao, Y. Li, H. Yan, D. Li and S. Chen, "Energy flow modeling and optimal operation analysis of micro energy grid based on energy hub," Power System Technology, vol. 42, no. 1, pp. 179-186, 2018.

[5] V. Thang, Y. Zhang, T. Ha and S. Liu, "Optimal operation of energy hub in competitive electricity market considering uncertainties," International Journal of Energy and Environmental Engineering, pp. $1-12,2018$

[6] H. Wang, H. Zhang, C. Gu and F. Li, "Optimal design and operation of CHPs and energy hub with multi objectives for a local energy system," Energy Procedia, vol. 142, pp. 1615-1621, 2017.

[7] A. Dolatabadi, B. Mohammadi-Ivatloo, M. Abapour and S. Tohidi, "Optimal stochastic design of wind integrated energy hub," IEEE Transactions on Industrial Informatics, vol. 13, no. 5, pp.2379-2388, 2017.

[8] A. Sheikhi, A. Ranjbar, H. Oraee and A. Moshari, "Optimal operation and size for an Energy Hub with CCHP," Energy \& Power Engineering, vol. 3, no. 5, pp. 641-649, 2011.

[9] H. Fan, Q. Chen, W. Liu, J. Li and Y. Chen, "Optimal scheduling for energy hub in power markets," Proceedings of ISGT - Asia, pp. 127131, 2016.

[10] B. Liu, Q. Lin, T. Zheng, L. Chen and S. Mei, "Low carbon economic dispatch for multi-energy distribution network with compressed air energy storage system as energy hub," Proceedings of CCC, pp. 3083-3088, 2017.

[11] A. Sciacovelli, D. Smith, H. Navarro, Y. Li and Y. Ding, "Liquid air energy storage - Operation and performance of the first pilot plant in the world," Proceedings of ECOS, Slovenia, 2016.

[12] G. Brett, M. Barnett, "The application of liquid air energy storage for large scale long duration solutions to grid balancing," Proceedings of European Physical Journal Web of Conferences, pp. 03002, 2014.

[13] A. Berrada, K. Loudiyi; "Optimal Modeling of Energy Storage System," International Journal of Modeling and Optimization, vol. 5, no. 1, pp. 71-77, 2015.

[14] Y. Hu, X. Li, H. Li and J. Yan, "Peak and off-peak operations of the air separation unit in oxy-coal combustion power generation systems," Applied Energy, vol. 112, no. 16, pp. 747-754, 2013. 